\title{
СОЦИОЛОГИЯ
}

И СОЦИАЛЬНЫЕ ТЕХНОЛОГИИ

DOI: https://doi.org/10.15688/lp.jvolsu.2019.1.5

UDC 316.422

LBC 60.561 .2

\section{ROLE OF DIGITAL ECONOMY IN THE DEVELOPMENT OF LIFELONG EDUCATION SYSTEM}

\author{
Igor E. Zolin
}

Nizhny Novgorod Institute of Management - Russian Presidential Academy of National Economy and Public Administration Branch under the President of the Russian Federation, Nizhny Novgorod, Russian Federation

\begin{abstract}
The author represents the economic and sociological analysis of modern features of digital economy and its role in the development of the system of lifelong education. A distinctive feature is the combination of problem and applied approaches to the analysis of the designated topic. The study is carried out on the basis of the method of identifying the essential characteristics of the digital economy taking into account the innovative nature of modern socio-economic development. This stage of development is characterized by a number of stable global trends, which, in turn, significantly change the requirements for the qualification of employees, the content and methods of their training highlighting the issues of ensuring the continuity of the educational process. Assuming high dynamics of the economy and, consequently, rapid adaptation of labor force to the technological changes the author shows, that at the present stage of society development one of the main tasks is to achieve a sharp increase of labor productivity, through which the effectiveness of a new type of economic and social relations should be manifested. The labor process of workers in the digital economy should become more diverse, meaningful and their production skills are much higher. The growth of the company's needs for more and more qualified personnel with a corresponding decrease in demand for low-skilled workers is caused by an increase in the technical level of production. It is dictated by the entire course of modern social and economic development associated with the expansion of information technologies use. The author suggests, that under these conditions, the system of lifelong education should be focused not only on the amount of theoretical knowledge and certain skills, but mainly on practice, the development of methods of analysis, the development of those qualities that allow the specialist to adapt to changing conditions quickly.

The article represents the data of sociological research carried out on the basis of in-depth expert interviews. In his conclusions, the author also relied on his own experience in the development of this problem.

Key words: digital economy, lifelong education, state regulation, information technologies, labor market, scientific and technical progress, universities.
\end{abstract}

УДК 316.422

ББК 60.561 .2

\section{РОЛЬ ЦИФРОВОЙ ЭКОНОМИКИ В РАЗВИТИИ СИСТЕМЫ НЕПРЕРЫВНОГО ОБРАЗОВАНИЯ}

\author{
Игорь Евгеньевич Золин
}

Нижегородский институт управления - филиал Российской академии народного хозяйства и государственной службы при Президенте РФ, г. Нижний Новгород, Российская Федерация 
Аннотация. В статье дается экономико-социологический анализ современных особенностей цифровой экономики и ее роли в развитии системы непрерывного образования. Отличительной чертой является сочетание проблемного и прикладного подходов к анализу обозначенной темы. Исследование проводится посредством выявления сущностных характеристик цифровой экономики с учетом инновационного характера современного социально-экономического развития. Данному этапу развития присущ ряд устойчивых глобальных тенденций, что, в свою очередь, существенно изменяет требования к квалификации работников, содержанию и методам их профессиональной подготовки, выдвигая на первый план вопросы обеспечения непрерывности образовательного процесса. Показано, что на современном этапе развития общества, предполагающем высокую динамичность экономики и, следовательно, быструю адаптацию рабочей силы к происходящим в ней технологическим сдвигам, одной из главных задач становится достижение резкого роста производительности труда, через которую должна проявиться эффективность нового типа экономических и социальных отношений. Трудовой процесс работников в условиях цифровой экономики должен стать разнообразнее, содержательнее, а их производственная квалификация намного выше. Рост потребностей общества во все более квалифицированных кадрах при соответствующем снижении спроса на работников низкой квалификации обусловливается повышением технического уровня производства, диктуется всем ходом современного социально-экономического развития, связанного с расширением применения информационных технологий. В этих условиях система непрерывного образования должна ориентироваться не только на объем теоретических знаний и определенные навыки, но главным образом на практику, освоение методов анализа, развитие тех качеств, которые позволяют специалисту быстро приспособиться к меняющимся условиям.

В статье использованы данные социологического исследования, осуществленного на базе глубинных экспертных интервью. В своих выводах автор опирался также на собственный опыт разработки указанной проблематики.

Ключевые слова: цифровая экономика, непрерывное образование, государственное регулирование, информационные технологии, рынок труда, научно-технический прогресс, вузы.

\section{Введение}

В развитии современного общества прошедшие десятилетия заняли специфическое место - речь идет о качественно новом этапе научно-технического прогресса. Вступление в новый этап глобально, а связанные с ним перемены широко трактуются как решительный переход современной экономики в цифровую плоскость. При этом достаточно отчетливо признается качественное отличие цифровизации современной экономики, стартовавшей в последние годы, от ее прежних форм. Например, совершенно иным стало положение с обеспечением производства основными ресурсами, в том числе трудовыми [Куприяновский и др. 2016; Сизова, Хусяинов 2017]; видоизменились роли отдельных сфер экономики [Ерешко, Меденников 2018; Куприяновский и др. 2017], под влиянием обозначенных процессов в состоянии перестройки находится социальная сфера, общественная и частная жизнь, сфера образования [Иудин, Шпилёв 2015; Колесник 2018; Саралиева, Захарова 2018]. Все это дает основание говорить некоторым исследователям о цифровой револю- ции [Бобков, Новикова, Шичкин 2016; Глазьев 2018; Карцхия 2017], в результате которой роль человека и непрерывного обновления его знаний неуклонно возрастают [Семенов web; Цифровая революция в медицине... web; Цифровая революция и электронное обучение web]. Следовательно, цифровая экономика связана не только с миром информационных технологий, компьютеров, электроники, роботов, но и с развитием человека - его разума, уникальности, многообразия его личностных проявлений.

Современные темпы развития цифровой экономики таковы, что продолжительность существования ряда профессий оказывается короче, чем период трудовой деятельности человека, а изменение содержания труда по ряду из них способствует появлению новых, связанных с созданием искусственных частей тела человека, наномедициной, производством генетически модифицированных растительных культур и животных [Talwar, Hancock web]. Согласно оценкам оксфордских исследователей данной проблемы, развитие цифровых технологий будет способствовать тому, что в бли- 
жайшие 10-25 лет перестанет существовать около $50 \%$ профессий [Frey, Osborne web]. Прогнозируется также, что в России должна появиться «профессия будущего»судья беспилотных автомобилей [Балясникова web], а 67 \% сегодняшних школьников будут работать в тех профессиях, которые сегодня попросту не существуют [Революция в образовании... web]. В этом случае формирование цифровой экономики представляется, по существу, как новый этап в развитии общества, который требует модернизации как образовательной системы, так и традиционного инструментария политики занятости, исследование которого было представлено нами ранее [Золин 2013].

Необходимость решения этих важных задач, требующих значительных экономических затрат, правовой регламентации, единой статистической информации, организационного руководства, определяет усиление роли государства в развитии этого процесса. Фактически построение государством цифровой экономики как развивающийся во времени и пространстве процесс включает три логические стадии, ориентированные на достижение конкретного результата: разработку концепции; перевод общего замысла на язык законов и государственных решений; их практическую реализацию. Будучи тесно взаимосвязанными, эти стадии тем не менее обладают своей автономной динамикой, и, следовательно, каждая из них имеет собственный баланс позитивных и негативных тенденций. В этой связи осуществляемые в настоящее время в России мероприятия по стимулированию развития цифровой экономики свидетельствуют о возрастании значения новой сферы государственного регулирования - сферы формирования информационного потенциала и внедрения информационных технологий [Распоряжение Правительства РФ от 28.07.2017...; Указ Президента РФ от 09.05.2017...].

Именно эти обстоятельства определяют новый подход к формированию современной концепции перспективного развития образования, меняют существующий принцип организации этой системы, выдвигая в качестве важнейшей задачу обеспечения его непрерывности.

\section{Материалы и методы}

В данной работе представлены некоторые результаты социологического исследования «Проблемы и перспективы развития рынка труда России», проведенного автором в 2018 г. с использованием метода глубинных экспертных интервью. Опрос экспертов осуществлен в Нижнем Новгороде в мае - июле 2018 г., анализ результатов - в августе - ноябре 2018 года. Было опрошено 20 экспертов, в состав экспертной группы вошли работодатели, имеющие опыт практического профессионального взаимодействия со специалистами разного уровня и профиля деятельности, а также преподаватели вузов, сочетающие педагогическую и научную работу с успешной практической деятельностью. Возраст участников опроса находился в диапазоне от 33 до 68 лет, при этом количество мужчин и женщин было примерно одинаковым. В ходе исследования было выявлено 26 сюжетных линий, две из которых напрямую касались проблем непрерывного образования, а также представлений экспертов о цифровой экономике. Характеристика этих двух сюжетных линий представлена в настоящей статье.

\section{Обсуждение и результаты}

В понимании экспертов, принявших участие в исследовании, термин «цифровая экономика» имеет две стороны. С одной стороны, это автоматизированное управление производственными, технологическими, социальными и кадровыми процессами с использованием информационных продуктов. В этом плане цифровая экономика характеризуется преобладающей ролью IT-технологий во всех сферах жизни общества. С другой стороны, цифровая экономика - это специфическая часть материально-технологической базы общества, в которой информационная индустрия характеризуется как отрасль, основанная на информационно-вычислительном обслуживании и программировании, разработке средств и процессов обработки и передачи информации.

Если в первом случае цифровая экономика рассматривается как сфера непосредственного применения IT-технологий незави- 
симо от того, в каких бы секторах экономики и социальной сферы ни использовались информационные продукты, то во втором - как сфера производства научно-технологической информации и ее практического приложения. При этом все эксперты едины во мнении, что для современного этапа развития характерно дальнейшее совершенствование информационных технологий, расширение их применения. Человечество без развития информационных систем, передачи информационных функций от человека к машинам уже не может представить свое дальнейшее существование.

Внедрение цифровой экономики изменило организацию финансовых расчетов (электронные деньги, автоплатежи), медицинского обслуживания (цифровая диагностическая аппаратура, электронные картотеки истории болезни), индустрию досуга (цифровое телевидение), домашний быт (цифровая бытовая техника, цифровое ЖКХ), получение образования (автоматизированные обучающие системы), взаимодействие органов государственной власти и общества (госуслуги через Интернет), оптимизировало государственную систему управления (электронноцифровая подпись, центры обработки данных), функционирование транспортной системы (ГЛОНАСС и GPS-контроль движения, умный светофор, умные остановки), предоставление услуг связи (цифровая телефония), развитие производственной инфраструктуры (цифровизация промышленности, сельского хозяйства, строительства).

В этой ситуации, с точки зрения большинства экспертов (16 человек), вся система государственного управления должна быть ориентирована на стимулирование хозяйствующих субъектов к скорейшему внедрению и освоению новой техники и технологий, на создание условий, при которых предприятия буквально гонялись бы за новинками, чтобы они не могли жить без освоения новой продукции. Но, как показывает практика последних лет, далеко не все предприятия способны к этому, во-первых, по причине дороговизны средств комплексной цифровизации производственных процессов; вовторых, по причине риска, связанного с переходом на новую технологию в условиях крайне нестабильной хозяйственной конъюнктуры, изменения правил игры в экономике.
«Чтобы развивать цифровую экономику, необходимы реальные шаги, связанные с тем, чтобы предприятия были готовы постоянно вести модернизацию своего производства, думать о том, как обновить технологический процесс, какая продукция востребована на рынке. Если мы говорим про бизнес, то нужно, чтобы правила игры со стороны государства не менялись хотя бы лет 5, необходимо заморозить тарифы, налоги, процентные ставки по кредитам» (из интервью с экспертом по промышленности, общественным деятелем).

По мнению всех опрошенных экспертов, воздействие цифровой экономики на динамику, структуру и эффективность производства сказывается в том, что на ее основе перестраиваются традиционные отрасли народного хозяйства, изменяются методы переработки сырья и повышается качество выпускаемой продукции; обработка ведется качественно новыми техническими средствами и технологическими методами; экономится рабочее время, рационализируется использование энергии, материалов, производственных площадей; увеличивается потребность хозяйства во все более квалифицированных кадрах при соответствующем снижении спроса на работников низкой квалификации.

«Развитие цифровой экономики повлечет за собой очень много изменений во всех отраслях. Потребуются другие знания, другие специалисты. Эта перестройка, ломка, естественно, заденет многих... Спрос на работников низкой квалификации будет неизбежно снижаться, а высококлассный специалист, который имеет хорошее образование, в цифровой экономике будет наиболее востребован» (из интервью с исполнительным директором банка с государственным участием).

Таким образом, цифровая экономика предъявляет повышенные требования к образованию и подготовке кадров. Усложнение производства, развитие новых и новейших отраслей экономики, необходимость проведения научных исследований требуют совершенствования системы непрерывного образования, так как дальнейшее развитие производства невозможно без использования высококвалифицированной рабочей силы.

В этих условиях привычные важнейшие количественные показатели системы образова- 
ния (численность учащихся, охват населения различными его формами, среднее количество лет обучения и т. п.) утрачивают свое доминирующее значение. Развитие образования в экстенсивных формах становится неоправданным. Все это требует принципиально нового подхода, при котором основные показатели системы образования и подготовки кадров должны определяться потребностями формирующейся цифровой экономики. В этой связи, чтобы рельефнее высветить обозначенную проблему, перед экспертами был поставлен вопрос относительно сущности понятия «непрерывное образование», а также вопрос о возрастных границах получения человеком образования, необходимости его непрерывного совершенствования в современных условиях.

Здесь мнения экспертов разделились. Одна группа экспертов (7 человек) считает, что непрерывное образование - это образование на протяжении трудовой жизни человека, которое предполагает органическое сочетание общего и профессионального образования с последующим постоянным повышением квалификации работника, а также, в случае необходимости, его переквалификацию. Такое образование связано с осуществлением человеком профессиональной деятельности и занимает в его жизни определенный отрезок времени, пока он существует в профессии. Требуется планомерная, систематическая профессиональная учеба в течение всей трудовой жизни работника, чтобы он был готов постоянно трудиться на новом оборудовании и, исходя из потребностей производства, мог менять вид трудовой деятельности.

Другая группа экспертов (13 человек) полагает, что непрерывное образование - это постоянно возобновляемое образование, направленное на совершенствование человеком своих знаний и навыков в течение всей своей жизни. В этом случае в идее непрерывного образования должна быть заложена определенная процедура, логические шаги с тем, чтобы каждое звено образовательной системы работало на общий конечный результат. Дошкольные учреждения, школа, средние специальные и высшие учебные заведения, научно-техническая пропаганда и информация, повышение квалификации в самых разнообразных формах (спецкурсы, семинары, мас- тер-классы, стажировки на предприятиях, участие в специализированных выставках и т. п.), самообразование - все это, по мнению экспертов данной группы, звенья единой системы непрерывного образования.

Таким образом, диапазон формирования образованной личности в системе непрерывного образования, как видно, может быть достаточно широк: от ранней профессионализации до мастерства классного специалиста и всесторонне развитого человека. Это предполагает как осознание человеком приоритетности образования, формирование у него всеохватывающей мотивационной политики, направленной на постоянное повышение в течение всей своей жизни профессионального и общеобразовательного уровня (принцип добровольности), так и создание условий, связанных с возможностью получения образования в любом возрасте в соответствии с его потребностями и интересами (принцип доступности). При этом система непрерывного образования должна обладать определенной гибкостью - учитывать потребности отдельных лиц в образовании, а также прогнозируемую эволюцию экономических отношений, изменения в социальной и трудовой сфере.

Важную роль в проблеме обеспечения непрерывной подготовки специалистов, по мнению половины экспертов, способны сыграть вузы, которые при комплексном подходе могут выступить своеобразным интегратором кооперации между учебными заведениями и отраслями народного хозяйства. Важная составляющая организации непрерывного образования в этом случае заключается в том, что повышенная заинтересованность обращающихся к их услугам людей, с одной стороны, должна способствовать интенсификации обучения, а с другой - выдвигать на первый план особые требования к формированию учебных программ, к средствам обучения в соответствии с динамикой развития цифровой экономики и связанными с ней общественными и индивидуальными потребностями.

Соглашаясь в целом с подобной точкой зрения, заметим в этой связи, что в России наиболее высокий уровень подготовки дают национальные исследовательские университеты, где достаточно качественный уровень преподавания поддерживается соответствующими 
научными исследованиями и реализацией инновационных образовательных программ. В настоящее время в стране насчитывается 29 национальных исследовательских университетов [Национальные исследовательские университеты... web]. В то же время в топ-100 глобального рейтинга «Три миссии университета» в 2018 г. вошли только три российских университета: Московский государственный университет им. М.В. Ломоносова, Санкт-Петербургский государственный университет, Московский физико-технический институт (государственный университет), которые заняли соответственно 23, 61 и 65 позиции в рейтинге [Московский международный рейтинг вузов... web].

Между уровнем образования людей и их желанием непрерывно его повышать, приобретать новую квалификацию, расширять свой кругозор, по мнению всех экспертов, существует тесная взаимосвязь. Повышение уровня профессионального образования усиливает их потребность в его совершенствовании. При этом человек не удовлетворяется получением образования в рамках только традиционных форм обучения и обращается ко всем каналам распространения знаний, интенсивным формам обучения с использованием информационных технологий, а также учебным программам, насыщенным прикладными задачами. Возрастает роль самообразования.

«Я уже на пенсии, скоро мне будет 62 года. Но пока есть возможность, пока есть силы, желание, я себя нашла в другом. У меня сегодня меньше педагогической деятельности, больше воспитательной и практической. Я теперь промышленный экскурсовод. Если хочешь, чтобы жизнь продолжалась, попробуйте себя в различных сферах» (из интервью с преподавателем вуза).

Важно иметь в виду и оборотную сторону отмеченной закономерности: чем ниже у человека образовательный уровень, тем меньше у него желания продолжать учебу, развивать свои умственные способности, проявлять творческую инициативу. Если это не учитывать в образовательной политике, то можно столкнуться с такой ситуацией, когда наряду с общим подъемом образовательного уровня населения будет иметь место его дифференциация и поляризация. С одной стороны, концентрация людей с неуклонно возрастающим образовательным и интеллектуальным цензом, с другой - растущее число людей, систематически отстающих в своем образовательном росте, что не может не сказаться и на их социальной и трудовой активности.

Понятно, что с помощью внедрения одной лишь новой техники и усовершенствованных технологических процессов, не дополненных организационными мероприятиями в национальном масштабе, построение современной цифровой экономики невозможно. Традиционно Россия - страна с очень сильной ролью государства, и во многом органы государственной власти оказывают влияние на направления социально-экономического развития. В данном случае со стороны государства необходимы и политическая воля, и усилия, и финансы.

Бурное развитие информационных технологий является своего рода техническим разрешением между масштабами современной экономики и возможностями ее государственного регулирования, поскольку последнее, как известно, основывается на своевременном принятии решений на основе достоверной и полной информации. В этом плане не будет преувеличением сказать, что большинство революционизирующих открытий современности связано с областью сбора, обработки, передачи и хранения информации, поэтому информационные технологии и их использование превратились в комплексный интегрирующий фактор развития экономики и социальной сферы.

Сегодня, однако, понятно, что рост динамики национальной экономики в плане широкого внедрения информационных технологий будет трудным и длительным процессом на всех стадиях, в ходе которого важно ставить реалистические задачи. По мнению четверти экспертов, долгосрочная тенденция, повидимому, такова, что ввиду определенной закрытости нашей страны из-за введенных санкций импорт технологий будет в перспективе необратимо свертываться, что может нанести определенный ущерб национальным интересам России.

«В свете того, что наша страна в последние годы была подвергнута определенным санкциям, Россия выставила в ответ контрсанкции. В ситуации, когда страна в технологическом плане отстает от многих развитых 
государств, санкции, примененные в отношении России, играют больше отрицательную роль, чем положительную. Закрытость страны, которая сейчас, на мой взгляд, носит угрожающий характер, в первую очередь наносит ущерб национальным интересам самой России» (управляющий региональным отделением коммерческого банка).

В связи с этим России придется привыкать к тому, что революционное технологическое обновление экономики и ее доведение до уровня мировых стандартов может затянуться по времени. Назревает даже нечто вроде замкнутого круга. Без закупок ноу-хау и передовой технологии едва ли удастся быстро сформировать цифровую экономику, расширить конкурентоспособный товарный экспорт, а без увеличения доходов от экспорта затруднительно поддержать многие виды производства на должном технологическом уровне.

Вопрос финансовой поддержки государством создания новых высокотехнологичных рабочих мест в условиях формирования цифровой экономики также следует рассматривать особо. Когда внутренние источники роста инвестиций в производство ограничены, а инвестиционный комплекс не всегда в состоянии освоить существенно больший объем инвестиций (в том числе из-за сбоев в инфраструктуре и худшего, по сравнению с потребностями, качества рабочей силы), программы инвестиционной поддержки создания новых высокоэффективных рабочих мест на рынке труда также могут быть труднореализуемыми, поскольку требуют значительных средств и времени. Однако если отечественная экономика впоследствии будет радикально перестроена и заработает на полную мощность, то вряд ли в будущем с помощью санкций извне удастся серьезно замедлить ее технологическое развитие.

Новые требования к качеству рабочей силы будут стимулировать спрос на людей с системным мышлением, их умением встроиться в цифровую экономику. Это предполагает постоянное обновление кадров, приток в их ряды энергичных, полных сил людей с современными знаниями и современными взглядами на жизнь. С другой стороны, около половины экспертов обеспокоены тем, что развитие цифровой экономики в России может привести к резкому вытеснению рутинных производственных процессов и высвободить достаточно много рабочих мест.

«Для людей цифровая экономика может обернуться плачевно, потому что цифровые технологии могут высвободить очень много рабочих мест. Сейчас мы об этом, по-моему, просто не задумываемся. В свое время в Советском Союзе много говорили об освобождении человека от части труда и передаче определенных функций новым технологиям. Предполагалось, что человек должен меньше работать, больше заниматься своим внутренним миром и развитием. На сегодняшний день это может обернуться совершенно другим образом - нехваткой рабочих мест, а не тем, что человек работает 4 часа и получает за это благодаря новым цифровым технологиям ту же зарплату» (из интервью с начальником учебно-методического отдела вуза).

Сокращение числа традиционных рабочих мест и появление новых, требующих большего объема знаний и навыков, расширение безлюдных технологий приведет к тому, что модернизация производства на отдельных этапах усилит риск безработицы и, как следствие этого процесса, категория работников расслаится на две основные группы: 1) работники, обладающие современными профессиями, высокой квалификацией, что обеспечивает им достаточную мобильность, оплату и относительно более стабильную занятость; 2) работники - обладатели традиционных профессий, которые могут трудиться в рамках сложившегося производства, где требования к рабочей силе значительно ниже. Эта группа более уязвима в отношении уровня оплаты труда, их занятость менее устойчива, профессиональное продвижение затруднительно.

В то же время 9 экспертов полагают, что в условиях развития цифровой экономики роста безработицы не произойдет: в ходе внедрения новых технологий могут возникнуть не только негативные для занятости трудосберегающие эффекты, но и трудорасширяющие. Это связано с одновременным развитием сферы услуг, которая будет притягивать освободившуюся рабочую силу из традиционных отраслей промышленности, строительства, сельского хозяйства. Данный труд потребуется для развития прогрессивных отраслей эко- 


\section{СОЦИОЛОГИЯ И СОЦИАЛЬНЫЕ ТЕХНОЛОГИИ}

номики. Эти эксперты отмечают, что по мере развития цифровой экономики и автоматизации производства произойдет перераспределение трудовых ресурсов. В частности, научно-технический прогресс неизбежно будет развивать систему образования, в том числе и с нетрадиционными секторами (например, разнообразные интернет-курсы), систему рекреации, досуга и обслуживания. Модернизацию и автоматизацию рабочих мест в условиях цифровой экономики нельзя недооценивать как фактор, способствующий новой сегментации рынка труда. На наш взгляд, комплексная модернизация и автоматизация способны привести, особенно на первоначальном этапе, к разрыву между наличной и необходимой численностью квалифицированных работников, прежде всего на вновь вводимых в эксплуатацию современных предприятиях.

В России практика последних лет показывает, что из-за нехватки квалифицированных кадров современное высокотехнологичное оборудование порой простаивает. Например, внедрение цифровых технологий в сфере индустрии здоровья - оснащение медицинских учреждений сложной диагностической, операционной и лечебной аппаратурой - привело к тому, что в ряде больниц персонал не в состоянии обслуживать передовое оборудование из-за недостаточной квалификации.

Примечательно, что цифровизация, являясь мощным средством трудосбережения в общественном масштабе, повышает долю прошлого труда в производстве, но одновременно существенно повышает роль живого, причем весьма квалифицированного труда в ремонте автоматизированной техники, обеспечении общих условий ее эффективной работы, контроля за производственным процессом. Отсюда напрашивается следующий вывод: набирая персонал, нельзя упускать из виду ту условную, но практически существующую на рынке труда разность в объемах фактической профессионально-квалификационной подготовки и ожидаемой, обусловленной объективными требованиями усовершенствованной техники и технологии.

Что касается качества рабочих мест на рынке труда, то здесь влияние цифровой экономики, на взгляд всех опрошенных экспертов, очевидно. Внедрение IT-технологий по- зволяет децентрализовать трудовую деятельность, организовать надомный труд в онлайнформате, обеспечив тесную взаимосвязь отдельных производственных функций, и, соответственно, повысить социально-трудовую мобильность рабочей силы. Все это неизбежно потребует непрерывного повышения образовательного уровня человека, расширения его технического кругозора. Другими словами, прорыв в развитии цифровой экономики можно осуществить лишь одним путем - непрерывным повышением уровня образованности общества, усилением и укреплением его интеллектуального потенциала.

\section{Выводы}

1. Цифровая экономика вносит качественные изменения в технологию производства, организацию управления, ведет к переменам в социальной сфере, образовании, меняет характер трудовой деятельности и связана со всеми сторонами повседневной жизни людей. При этом развитие цифровой экономики воздействует на систему образования двояким образом. Во-первых, возрастает необходимость более высокого качества подготовки как обучающихся, так и педагогов, массовой профессионализации подрастающего поколения и, наряду с этим, более высокого удельного веса фундаментальных знаний, широкой и разносторонней общей подготовки специалистов. Во-вторых, неуклонно расширяются границы получения человеком образования (возрастные, временные), в результате чего оно все больше приобретает характер непрерывного образования, или образования в течение всей жизни.

2. На современном этапе развития общества необходимо, чтобы в жизни любого человека постоянно присутствовало как обучение, так и трудовая деятельность. В этих условиях главной задачей образования являются создание «запаса» в уровне подготовки работников и непрерывное совершенствование их производственного профиля. Непрерывное образование призвано соединить в себе два важных требования к работнику: максимально возможную широту теоретических познаний и предельно достижимую на практике профессиональную квалификацию в определенной 
специальности на уровне виртуозного овладения ею. При этом важными принципами непрерывного образования в условиях цифровой экономики должны стать планомерность, добровольность, доступность, гибкость.

3. Внедрение информационных технологий во все звенья общественной жизни делает технически осуществимым вычленение человека из непосредственного процесса производства и тем самым разрушение жесткой сцепки «машина - человек». Это сделает понятие «рабочее место» чрезвычайно мобильным. В цифровой экономике открываются широкие возможности гибкой организации труда, маневрирования с распределением рабочего времени и численностью занятых, придания гибкости как рабочим местам, так и рабочей силе. Следовательно, в этих условиях будет существенно меняться и характер трудовой деятельности человека, что стимулирует необходимость непрерывного повышения образовательного уровня человека, расширения его технического кругозора. В этой ситуации высшие учебные заведения (прежде всего национальные исследовательские университеты), вбирая в себя и синтезируя все современные достижения, призваны сыграть определяющую роль в решении сложной проблемы непрерывного обогащения, обновления знаний и навыков специалиста в течение всей его профессиональной деятельности.

\section{СПИСОК ЛИТЕРАТУРЫ}

Балясникова web - Балясникова Д. В России в скором времени появится новая «профессия будущего» // http://nation-news.ru/424164-vrossii-v-skorom-vremeni-poyavitsya-novayaprofessiya-budushego.

Бобков, Новикова, Шичкин 2016 - Бобков В.Н., Новикова Н.В., Шичкин И.А. Цифровая революция и ее воздействие на устойчивость рынков труда и занятости // Уровень жизни населения регионов России. 2016. № 3 (201). С. 12-17.

Глазьев 2018 - Глазьев С.Ю. Информационно-цифровая революция // Евразийская интеграция: экономика, право, политика. 2018. № 1 (23). C. $70-83$.

Ерешко, Меденников 2018 - Ерешко Ф.И., Меденников В.И. Формирование цифровой платформы АПК // Проектирование будущего.
Проблемы цифровой реальности. 2018. № 1 (1). C. 65-73. DOI:10.20948/future-2018.

Золин 2013 - Золин И.Е. Рынок труда и политика занятости: новые возможности и старые проблемы // Вестник Нижегородского университета им. Н.И. Лобачевского. 2013. № 4-1. С. 282-286.

Иудин, Шпилёв 2015 - Иудин А.А., Шпилёв Д.А. Социальные проблемы модернизации страны и особенности сырьевой экономики // Вестник Нижегородского университета им. Н.И. Лобачевского. Серия: Социальные науки. 2015. № 3 (39). С. 85-92.

Карцхия 2017- Карихия А.А. Цифровая революция: новые технологии и новая реальность // Правовая информатика. 2017. № 1. С. 13-18.

Колесник 2018 - Колесник А.П. Социальные системы в цифровой экономике // Стратегии бизнеса. 2018. № 1 (45). C. 3-11. DOI: http://doi.org/ 10.17747/2311-7184-2018-1-03-11.

Куприяновский и др. 2016 - Куприяновский В.П, Конев А.В., Синягов С.А., Намиот Д.Е., Куприяновский П.В., Замолодчиков Д.Г. Оптимизация использования ресурсов в цифровой экономике // International Journal of Open Information Technologies. 2016. T. 4, № 12. С. 86-96.

Куприяновский и др. 2017 - Куприяновский В.П., Синягов С.А., Намиот Д.Е., Уткин Н.А, Николаев Д.Е, Добрынин А.П. Трансформация промышленности в цифровой экономике экосистема и жизненный цикл // International Journal of Open Information Technologies. 2017. Т. 5, № 1. С. 34- 49 .

Московский международный рейтинг вузов... web Московский международный рейтинг вузов «Три миссии университета»: [итоговая таблица] // https://mosiur.org/ranking/.

Национальные исследовательские университеты... web - Национальные исследовательские университеты: 29 вузов // http://www.edu.ru/ vuz/niu.

Распоряжение Правительства РФ от 28.07.2017...Распоряжение Правительства РФ от 28.07.2017 № 1632-р «Об утверждении программы “Цифровая экономика Российской Федерации”» // Собрание законодательства Российской Федерации. 2017. № 32. Ст. 5138.

Революция в образовании... web - Революция в образовании - мифы или реальность? На экономическом форуме обсуждали настоящее и будущее образования // http://prosv.ru/news/ show $/ 2526 . \mathrm{html}$.

Саралиева, Захарова 2018 - Саралиева 3.X., Захарова Л.Н. Поддерживающий тип поведения как ключевая компетенция менеджеров и педагогов программ развития цифровых 
компетенций женского персонала // Гендерное измерение цифровой экономики: от стратегии к действию : материалы Всерос. конф. с междунар. участием. Иваново: Иван. гос. ун-т, 2018. С. 24-28.

Семенов web-Cеменов Д. Цифровая революция и рынок труда // http:/www.rg-rb.de/index.php? option $=$ com_rgchik\&task=item\&id=4355.

Сизова, Хусяинов 2017-Сизова И.Л., Хусяинов Т.М. Труд и занятость в цифровой экономике: проблемы российского рынка труда // Вестник Санкт-Петербургского университета. Социология. 2017. Т. 10, № 4. С. 376-396.

Указ Президента РФ от 09.05.2017... - Указ Президента РФ от 09.05.2017 № 203 «О Стратегии развития информационного общества в Российской Федерации на 2017-2030 годы» // Собрание законодательства Российской Федерации. 2017. № 20. Ст. 2901.

Цифровая революция в медицине... web - Цифровая революция в медицине диктует новые условия медицинскому образованию в России // http:// www.sechenov.ru/pressroom/news/tsifrovayarevolyutsiya-v-meditsine-diktuet-novye-usloviyameditsinskomu-obrazovaniyu-v-rossii-/.

Цифровая революция и электронное обучение web - Цифровая революция и электронное обучение // http://m-profobr.com/files/--------_ptbnp0wq.pdf.

Frey, Osborne web - Frey C.B., Osborne M.A. The Future of Employment: How Susceptible Are Jobs to Computerization? Oxford Martin School, Programme on the Impacts of Future Technology // http://www.oxfordmartin.ox.ac.uk/downloads/ academic/The_Future_of_Employment.pdf.

Talwar, Hancock web - Talwar R., Hancock $T$. The Shape of Jobs to Come. Possible New Careers Emerging from Advances in Science and Technology (2010-2030). Fast Future Research // http://fastfuture.com/wp-content/uploads/ 2010/01/FastFuture_Shapeofjobstocome FullReport1.pdf.

\section{REFERENCES}

Balyasnikova D. In Russia will soon be a new "profession of the future". URL: http://nationnews.ru/424164-v-rossii-v-skorom-vremenipoyavitsya-novaya-professiya-budushego (accessed 6 January 2019).

Bobkov V.N., Novikova N.V., Shichkin I.A., 2016. The digital revolution and its impact on the sustainability of labour and employment markets. Uroven' zhizni naseleniya regionov Rossii, no. 3 (201), pp. 12-17.
Glaz'ev S.Yu., 2018. The digital revolution. Evrazijskaya integraciya: ehkonomika, pravo, politika, no. 1 (23), pp. 70-83.

Ereshko F.I., 2018. Formation of a digital platform of agroindustrial complex. Designing the future. Problems of digital reality. Moscow, IPM them. M.V. Keldysh, pp. 65-73. DOI:10.20948/future2018.

Zolin I.E., 2013. Labour market and employment policy: new opportunities and old problems. Vestnik Nizhegorodskogo universiteta im. N.I. Lobachevskogo, no. 4-1, pp. 282-286.

Iudin A.A., Shpilyov D.A., 2015. Social problems of modernization of the country and features of the commodity economy. Vestnik Nizhegorodskogo universiteta im. N.I. Lobachevskogo. Seriya: Social'nye nauki, no. 3 (39), pp. 85-92.

Karckhiya A.A., 2017. The digital revolution: new technologies and a new reality. Pravovaya informatika, no. 1, pp.13-18.

Kolesnik A.P., 2018. Social systems in the digital economy. Strategii biznesa, no. 1 (45), pp. 3-11. DOI: http://doi.org/10.17747/2311-7184-2018-103-11.

Kupriyanovskij V.P., Konev A.V., Sinyagov S.A., Namiot D.E., Kupriyanovskij P.V., Zamolodchikov D.G., 2016. Optimizing the use of resources in the digital economy. International Journal of Open Information Technologies, Vol. 4, no. 12 , pp. 86-96.

Kupriyanovskij V.P., Sinyagov S.A., Namiot D.E., Utkin N.A, Nikolaev D.E., Dobrynin A.P., 2017. Industrial transformation in the digital economyecosystem and life cycle. International Journal of Open Information Technologies, Vol. 5, no. 1, pp. 34-49.

Moscow international ranking of universities "Three missions of the University”: the final table. URL: https://mosiur.org/ranking/ (accessed 6 January 2019).

National research universities: 29 Universities. URL: http:/ /www.edu.ru/vuz/niu (accessed 13 January 2019).

Government order 28.06.2017 no. 1632-r "About the approval of the program 'Digital economy of the Russian Federation". Sobranie zakonodatel'stva Rossijskoj Federacii, 2017, no. 32, Art. 5138.

Revolution in education-myths or reality? The economic forum discussed the present and future of education. URL: http://prosv.ru/news/ show/2526.html (accessed 9 January 2019).

Saralieva Z.H., Zaharova L.N., 2018. Supporting type of behavior as a key competence of managers and teachers of digital competence development programs for female staf. Gender dimension of the digital economy: from strategy to action: materials 
of the All-Russian conference with international participation. Ivanovo, Ivan. gos. un-t, pp. 24-28.

Semenov D. The digital revolution and the labour market.URL: http://www.rg-rb.de/index.php? option $=$ com_rgchik\&task $=$ item $\& i d=4355$ (accessed 12 January 2019).

Sizova I.L., Husyainov T.M., 2017. Labor and employment in the digital economy: problems of the Russian labor market. Vestnik SanktPeterburgskogo universiteta. Sociologiya, Vol. 10, no. 4, pp. 376-396.

The decree of the President of the Russian Federation from 09.05.2017 no. 203 "On the strategy of information society development in Russian Federation to 2017-2030 years". Sobranie zakonodatel'stva Rossijskoj Federacii, 2017, no. 20, Art. 2901.

Digital revolution in medicine dictates new conditions for medical education in Russia. URL: http://www.sechenov.ru/pressroom/news/ tsifrovaya-revolyutsiya-v-meditsine-diktuetnovye-usloviya-meditsinskomu-obrazovaniyuv-rossii-/ (accessed 15 January 2019).

The digital revolution and e-learning. URL: http:// $\mathrm{m}$-profobr.com/files/__ _ ptbnp0wq.pdf (accessed 20 January 2019).

Frey C.B., Osborne M.A. The future of employment: How susceptible are jobs to computerization?, Oxford Martin School, Programme on the Impacts of Future Technology. URL: http:// www.oxfordmartin.ox.ac.uk/downloads/ academic/The_Future_of_Employment.pdf (accessed 9 January 2019).

Talwar R., Hancock T. The shape of jobs to come. Possible New Careers Emerging from Advances in Science and Technology (20102030). Fast Future Research.URL:http:// fastfuture.com/wp-content/uploads/2010/01/ FastFuture_Shapeofjobstocome_FullReport1.pdf (accessed 20 January 2019).

\section{Information about the Author}

Igor E. Zolin, Candidate of Sciences (Economy), Associate Professor, Department of Economic Theory, Nizhny Novgorod Institute of Management - Russian Presidential Academy of National Economy and Public Administration Branch under the President of the Russian Federation, Prosp. Yu. Gagarina, 46, 603950 Nizhny Novgorod, Russian Federation, iz.iz2016@yandex.ru, https://orcid.org/0000-0001-5793-2421

\section{Информация об авторе}

Игорь Евгеньевич Золин, кандидат экономических наук, доцент кафедры экономической теории, Нижегородский институт управления - филиал Российской академии народного хозяйства и государственной службы при Президенте РФ, просп. Ю. Гагарина, 46, 603950 г. Нижний Новгород, Российская Федерация, iz.iz2016@yandex.ru, https://orcid.org/0000-0001-5793-2421 